\title{
Seeking Information in Circles: The Application of Chatman's Life in the Round Theory to the Information Small World of Catholic Clergy in Northern Nigeria
}

Journal of Information Science $1-15$

(C) The Author(s) 2015

Reprints and permissions: sagepub.co.uk/journalsPermissions nav

DOI: $10.1177 / 0165551510000000$ jis.sagepub.com ACA E

\section{Jacob Dankasa}

College of Information, University of North Texas, Denton, USA

\begin{abstract}
This study explores Chatman's proposition of the theory of life in the round that members of a small world who live in the round will not cross the boundaries of their world to seek information. The study tests Chatman's proposition to find out whether it is applicable to the special population of Catholic clergy. The study was conducted with Catholic clergy from Northern Nigeria. Findings show these clergy are not likely to cross boundaries of their small worlds to seek information about their ministry or private lives. They prefer to seek such information within their circle of clergy. The findings align with Chatman's conclusion that life lived in the round has a negative influence on information seeking. This study advances the understanding of Chatman's theory of life in the round and positions religious status as a factor that is capable of influencing the information seeking process.
\end{abstract}

\section{Keywords}

Information seeking behavior; small worlds; life in the round; clergy

\section{Introduction}

Chatman popularized the concept of the small world in developing her theories in information behavior research. A small world describes a world where the members share similar opinions and concerns, and understand each other because of the customs and language they uniquely share [1]. Chatman developed most of her theories based on the study of special populations. These special populations include prisoners [2], the poor [3], custodial workers [4], and women [5, 6]. Thompson [7] and Pollock [8] described the process of the development of Chatman's theories as information poverty research.

Following Chatman, other information scientists have tried to explore the small world of various groups or populations [9-11]. According to Pettigrew, Fidel, and Bruce, Chatman's conceptual frameworks are emerging as contributing frameworks for information behavior research, and "it is expected that her frameworks will be tested widely in a variety of settings" [12, p. 57]. However, despite the growing research exploring the intersection of information and religion, to date, a study of the small world of religious professionals within the African context is yet to be seen. There are no studies that explore how Catholic clergy in an African culture which views celibacy as abnormal decide what information is important to them, and what factors influence the choices they make on how they seek, use, and handle information. In addition, since Chatman's theories were mostly developed around the poor and marginalized people of the society, a study of Catholic clergy in a part of Africa may help in further understanding whether Chatman's theory could also be applicable to a set of people that may not be considered marginalized, but are in every sense of the word, privileged people who occupy positions of influence because of their religious status as clergy, while at the same time living in an environment that is largely considered underdeveloped. A study focusing on this perspective is lacking in the information science literature. This study intends to fill this gap. 


\subsection{Study Setting and Context}

Religion is a very vibrant and strong institution in Nigeria with the country's population almost equally distributed between Christians and Muslims. The clergy are substantially influential in the lives of the people. This study involves Catholic clergy working in the Northern part of Nigeria. Northern Nigeria (consisting of the Middle Belt) is made up of 19 of the 36 states of Nigeria, including the federal capital. The Catholic Church has three ecclesiastical provinces in Northern Nigeria and 22 dioceses in the three provinces. Northern Nigeria has a high concentration of Muslims in the far North who live side-by-side with the minority Christians. The Christians are, however, majority in the Middle Belt with a large and growing Catholic population. The region has experienced myriads of religious crises over the years. There are over 6,000 Catholic clergy in Nigeria and more than 2,100 serve in the Northern dioceses.

Northern Nigeria is made up of numerous cultures and tribes, which are independent of each other. It has a combination of rural and urban areas, with a high rate of poverty, especially in the rural areas. The social divide between the rich and poor, educated and uneducated is substantial. There are a few public libraries distributed across the states of the region. However, numerous institutions of higher education have their own library systems.

It must be noted, however, that the clergy in this environment enjoy a privileged position because of their religious and social status. They have influence over a large number of local people because of their role as leaders of congregations in both cities and the rural village communities. In this environment, communal life is highly praised and appreciated, which leads to increased social networks in which information moves and circulates among and between people. In such a society, many factors such as level of education, social status and the nature of one's profession influence the way of life of the people. The Catholic clergy in Nigeria live not only in this diverse geographical and socio-cultural environment, but also have to live according to the universal norms of the Catholic Church which are expected of Catholic clergy in general. They struggle to strike a balance between the expectations of local culture and the norms of the universal Church. These factors may likely influence their interactions with information.

This study particularly examines Catholic clergy who, in their religious vocation, are required to be celibates. The study classifies Catholic clergy as a special population because of their peculiar status as celibates and the nature of their profession. Celibacy is the state of being unmarried and remaining chaste for life. Celibacy as a state of life and the environment in which they live guide the social norms of the Catholic clergy in Nigeria; priests are seen as sacred, which leads to a much-scrutinized way of life. Where the priest goes, whom he relates with, and what he does and says matter. Chatman's theory of life in the round proposed that social norms held by a group cause private behavior to receive increased public scrutiny [2]. This increased scrutiny influences members of such a group to develop a certain way of life, or tactics such as secrecy, deception and avoidance of risk, that may help them make sense of information. This may lead to living life in the round. According to Chatman, members of a small world who live in the round will not go out of their world to seek information.

This paper reports on a section of findings drawn from a larger doctoral research project [13] that explored and described the information use environment of Roman Catholic clergy in Nigeria in relation to their information seeking behavior. The section of the larger study reported in this paper particularly assumes that the Catholic clergy in Nigeria live in a small world which influences them to live life in the round. It investigates how the small world contextualization of these clergy affects their interaction with information. This paper explores Chatman's conclusion that life lived in the round has a negative influence on information seeking [2]. The conclusion was based on the fifth proposition of her theory of life in the round, namely, that members of a small world who live in the round will not cross the boundaries of their world to seek information. This study tests Chatman's proposition to find out whether it is applicable to this special population of Catholic clergy. Specifically, the study tries to find out whether Catholic clergy in Nigeria prefer to remain within their group of clergy to look for information or will cross boundaries to seek information from those considered to be outsiders, with particular reference to human sources.

This section of the report answers one research question: How does the small world of the Catholic clergy in Nigeria fit into Chatman's proposition that "members who live in the round will not cross the boundaries of their world to seek information"?

This study advances the understanding of Chatman's theory of life in the round to other special populations that have not been previously studied. It furthers the understanding of the influence of religious status on the information behavior of a group of information users such as the Catholic clergy. This may be useful in positioning religious status as a factor that is capable of influencing the information seeking process. The findings of this study present a unique perspective in the study of information seeking and the application of its theories to varying populations and settings. The paper shows the diverse nature of information science research extending to religious domains. This study may be relevant to information professionals and system developers in customizing information according to social norms and worldviews 
of this group of information users. Theological institutions in Africa may also find this study relevant as they prepare future clergy for the challenges that come with information seeking within the context of their culture and environment.

\section{Related work}

\subsection{Chatman's life in the round}

Chatman built her theories on marginalized populations. She developed numerous theories to explore this phenomenon $[1,2,14]$. The theory of life in the round was drawn from her research with women in prison [2]. According to Chatman, life in the round is "a life with an enormous degree of imprecision and, surprisingly, accepted levels of uncertainty" [2, p. 211]. This is a life where members understand the meaning of expressions and language used in the group. The values that members hold define what information is acceptable.

The theory of life in the round is based on four concepts: small world, social norms, worldview, and social types. A small world, which was the underlying concept of one of Chatman's previous studies [1], describes a world where the members share similar opinions and concerns and they understand each other because of the customs and language they uniquely share. In such a society, members share a common awareness of important information resources and how they can be accessed. They know who is important and reliable within the group and whom they can believe and trust. Members of a small world tend to think alike because they experience a similar social reality. The concept of social norms is important to this study because it describes certain activities and behaviors that define the members of the small world. These are the acceptable codes of behavior within the group. Following these norms will bring order to the group, while deviating from them will bring chaos. Catholic clergy is a group of people with a particular way of life and expected behavior where members of the group are expected to conform to the principles of their religious vocation. The group is influenced by its religious affiliation. Studies that investigate the influence of religious status on how information is sought or shared among a group such as the Catholic clergy and the factors that influence their behavior are lacking. The theory of life in the round is applied in this study to understand the information practices of these clergy based on the concepts of small world, social norms and worldview as explained by Chatman.

Chatman made six propositional statements to define her theory of life in the round. The fifth proposition was particularly crucial to this study. It states that "members who live in the round will not cross the boundaries of their world to seek information" [2, p. 214]. In looking at the characteristics of Catholic clergy, the theory of life in the round may help to determine whether their social norms influence their information seeking process. To understand such a population, it is best to examine their social environment and to view the meaning of information in their context. Chatman believed that "an individual's reality is a socially constructed reality" [2. p. 215]. It is worth finding out whether the social and cultural realities of the information environment of Catholic clergy are constructing their information seeking process. This study may help us to further understand how Chatman's theory of life in the round applies to information users identified by their religious characteristics.

\subsection{Chatman and Information Poverty}

Chatman's theories are better understood when viewed as a whole. Most of Chatman's theories flow from her rejection of the notion that information poverty is linked to economic poverty. Chatman's desire was to identify other factors that contribute to information poverty from the lived experience of the user. Her theory of life in a small world was explained in her paper on the impoverished life-world of outsiders [14]. Chatman stressed the relevance of the insider/outsider factor in the study of information. Being an insider or outsider plays an important role in how knowledge is acquired, used or defined. The world of the insider is different from the world of the outsider, and is defined by his or her worldview. Chatman described insiders as those whose:

lived-experiences are shaped by the fact that they share a common cultural, social, religious, etc., perspective. It is these common experiences that provide expected norms of behavior and ways to approach the world. They also define those things that are important to pay attention to and those that are not [14, p. 194].

According to Chatman [14], when people consider themselves insiders, they view themselves as having a common understanding of the world with shared norms and beliefs. They have a coded way of expression that relates to their types. As a result, they view others who do not share these common traits as outsiders and withhold certain information from them, sometimes because they feel outsiders do not understand their world. This results in a protective and 
secretive behavior where privileged information is withheld from outsiders. When an insider shares information with an outsider it is done at great risk based on the trust the outsider has established as a reliable source of information. Chatman relates this to information seeking behavior in which the protective action of insiders prevents them from seeking relevant information from outsiders or sharing information with them. According to Chatman, this may have a negative effect on the kind of information insiders acquire and use; hence being an insider can hinder access to relevant information that outsiders possess, and subsequently leads to information poverty. Chatman sees insiders' membership as a contributing factor to information poverty. The collective worldview of the world in which they live, which is defined by their social norms and determines information that is seen as important to seek or worth sharing, shapes the use of information by members.

Chatman [14] claimed that her studies could be used as frameworks to make observations on the information behavior of specialized populations because of their localized information needs and sources, especially the influence of their social norms on the choices they make concerning relevant information. To understand such a population, it is best to examine their social environment and to view the meaning of information in their context. This study tests Chatman's theory of life in the round to see how it can help us understand the influence of social norms on the choices these clergy make on what constitutes relevant information in their social and cultural environment. Studies with this perspective are lacking in the information seeking literature.

There are other researchers who have looked at the concept of the insider/outsider from two different perspectives. Spink and Cole discussed the concept of the insider from the perspective of the research participant [15]. They emphasized that insiders share some common values from within which influence their information seeking, and insiders see these values as more important than those coming from outside. Carey, McKechnie, and McKenzie, on the other hand, looked at the concept from the researcher's angle [16]. They believe that being an insider through sharing some characteristics with the participants has its advantages for the researcher because it opens the way for acceptance and openness.

Although Chatman sees insiders' membership as a contributing factor to information poverty and defines her concept of the small world in relation to the lived-experience of the poor, I believe that a small world conceptualization could be drawn from the social world of other types of populations, not necessarily those who are materially poor or marginalized. Studies of insider behavior that apply Chatman's theories in order to understand information behavior among people who are not considered as marginalized or materially poor are lacking. This study explores Chatman's theory focusing on this perspective. As Jaeger and Burnett emphasized, "small world is, ultimately, neither evaluative nor absolutely yoked to poverty, whether socio-economic or informational. As a concept it is neither negative nor positive, but rather descriptive..." [17, p. 21]. This study situated the Catholic clergy in a particular small world, not necessarily in terms of material poverty or the world of deception, secrecy and risk-taking as described by Chatman, but in terms of how members of a particular social group (i.e., religious group) view and use information. Taylor, for instance, alluded to the fact that some problems or information needs of users could be the product of their particular environment $[18,19]$. The Catholic clergy in Nigeria may be an example of these types of users. They may be faced with problems or questions that are particularly affected by their African environment and the embedded culture. These problems could also result from the nature of the profession itself and the chosen lifestyle of the clergy. The identification of these problems is very important to fulfilling the information needs of the clergy.

Chatman's theories have been applied in various studies [20-23]. Out of Chatman's many theories, the small world concept has received more attention in many studies [24-28]. Not much research has been done testing some of Chatman's specific theories or other propositions of her theories such as the propositions in the theory of life in the round [29]. There are studies that have reflected on several of Chatman's theories, including the life in the round theory [30-32]. The big picture in many studies that have used Chatman as framework has, in large part, involved using her small world concept as a general framework, rather than testing the application of her specific theories. This makes it unclear which of Chatman's theories was specifically tested. This study specifically tests the fifth proposition of Chatman's theory of life in the round.

\subsection{The clergy in information seeking research}

Several studies on the information seeking habits of the clergy are emerging [33-36]. While many of the studies were on Christian clergy from the Western world [37-39], only a few studied clergy from Africa, and these were mostly on Islamic clergy [40-42]. Very few of these studies of the clergy have tested the applicability of information seeking behavior models or theories with their study population. Dankasa found that many of the studies of the clergy used similar methodology repeatedly, so that they resulted in similar findings that were merely outlining different sources of 
information used without much theoretical construct [43]. There is a need to test more theoretical frameworks which demonstrate information behavior in a social context, with this special population whose life responsibilities center on the social network in which they live and work. The studies conducted with clergy in Africa [40-42], for instance, apart from the fact that they were conducted among Islamic clergy, concentrated only in one state of Nigeria, and mostly used the survey method. Using a variety of methods such as qualitative and mixed methods and applying information seeking models will help to further the understanding of the information practices of clergy in Africa. This paper, as part of a larger study, applied the qualitative method of research and tested an information seeking theory of life in the round in order to widen the scope of research in this area with the clergy.

A noteworthy study that examined the information seeking of clergy using notable theoretical frameworks is Wicks' [39]. Wicks' study was largely dependent on Dervin's sense-making theory and some combination of social network theory and role theory. He studied pastoral clergy to determine the work worlds and the work roles that guide how they search for information. He found that the work worlds and work roles of the clergy influence their information seeking behavior so that it takes place in either a closed or an open system. A closed system exists when the clergy seek information only within their world, and an open system exists when they seek information outside their world. Wicks' work seemed to support Chatman [2] to a certain extent, in that members of a small world do not go outside their boundaries to seek information, although Wicks' did not set out to test Chatman's theory.

There is a need for more research on the clergy that tests various information seeking models focusing on different perspectives beyond Wicks'. Wicks studied clergy of six different Christian denominations from Canada. Some groups of clergy are unique in their way of life and formation. An individual religious denomination (church) may have some unique roles or status for its clergy, such as the requirement of celibacy for Catholic clergy and their adoption of uniform liturgical practices globally. It may be interesting to study a block of the clergy from a single denomination to determine if there are unique factors that influence their information seeking practices. One of the studies [38] that examined a block of the clergy from one denomination (Baptist ministers) did not test any theoretical framework of information seeking. It concentrated instead on the sources the ministers used and what caused them to seek or stop seeking information. The present study intends to advance the study of the clergy by testing an information seeking framework that has not been previously applied in examining this group of information users.

Notably, apart from Wicks [39], who used the Catholic clergy as part of a larger sample with six other denominations, and Curran and Burns [37], who presented a study on the methodology for studying the information seeking of Catholic clergy, not much has been done to focus solely on exploring the information seeking behavior of the Catholic clergy. The Catholic Church as the largest single Christian denomination, with over 1.2 billion adherents and over four hundred thousand clergy globally deserves more attention. These previous studies that examined the Catholic clergy did not investigate how environmental or religious factors may influence their information seeking behavior. The present study takes into account the factors that may influence how Catholic clergy respond to their information needs especially in an African context that has not been given much attention in studies with clergy.

\section{Method}

This paper reports on a section of a larger doctoral research project [13] that collected both qualitative and quantitative data in a concurrent triangulation strategy of mixed-methods case study [44], using episodic interviews and survey techniques. However, this paper reports only the qualitative part of the section of the larger study. Therefore, the method presented here is specific to the qualitative data of the section reported.

\subsection{Study participants}

Fifteen Catholic clergymen from the Northern Catholic dioceses of Nigeria with varying years of experience and levels of education participated in telephone interviews. It was a purposive sample of clergymen. As purposive sampling, the researcher selected the participants based on some characteristics resulting from the researcher's knowledge of the population under study. Catholic priests with varying years of experience were invited to participate in the interviews. They were categorized on three levels based on their years of experience. Those with less than ten years of experience were considered younger priests and those with 10 to 19 years were considered middle priests. Those priests with 20 or more years of experience were categorized as older priests. Among those who participated in the interviews, five were less than 10 years in the priesthood, five were 10 to 19 years, and five were 20 or more years in the ministry. Years of experience in the ministry was used to classify the clergy, rather than age, because there are clergymen who entered the priesthood at an advanced age and they could fall within any of these groups. By church law, the minimum age for 
ordination into the Catholic priesthood is 25 years, and only males are ordained into the Roman Catholic priesthood; therefore, all participants in the study are males.

All participants were expected to have met the minimum academic requirement for ordination into the Catholic priesthood. They were expected to have passed through seminary training with at least three years of Theology training. Catholic priests in Nigeria are presently expected to go through four years of Philosophy and four years of Theology training. The current minimum academic qualifications are bachelor's degrees in both philosophy and theology. The term current is used because there are Catholic priests who were ordained many years ago when these degree requirements were not in place; therefore, they may not possess these qualifications. The common educational requirement for all priests across all ages is the completion of philosophy and theology studies. It should be noted, however, that a good number of Catholic priests have attained further education beyond the bachelor's degree. For example, some hold masters or doctoral degrees. Some have also undertaken further studies in different areas of specialization beyond that of philosophy and theology. Among the interview participants, eight were Master's degree holders, and seven had a Bachelor's degree or equivalent.

\subsection{Data collection}

The telephone interviews were carried out with individual participants. They were conducted between September and November of 2014 using a narrative method of data collection called episodic interview [45]. Individual research participants were asked to narrate experiences or episodes of information seeking practices in which they had engaged. They were prompted to recall episodes of these incidents and encouraged to tell their stories without interruption. Several questions were asked during the interviews. Examples of the questions relevant to the section of the report presented here include: Could you recall a time or episode when you were looking for information about the teaching of the church? Could you recall a time or episode when you were looking for information about health matters? Can you tell me about the environment where you live and the resources such as the presence of social amenities, water, accessible roads, etc? Was there any time you found or you did not find some information you looked for because of the environment where you live? Can you tell me things about your culture such as communal life, the value attached to marriage and procreation? As a celibate clergy, has this culture ever influenced the way you ask people for information or how you look for information from people? Can you give me an example of what you mean? Were there some kinds of information you looked for in the past that you preferred to ask a priest rather than to ask lay people about it? Can you give me an example of when you had such an experience? Follow-up questions were asked as needed. The telephone interviews were carried out through the audio function of Skype using software, affiliated with Skype, called Callburner. The software automatically recorded the conversation and saved it on a specified location in the interviewer's computer. The interviews lasted between 30 minutes and 1 hour 50 minutes.

\subsection{Data analysis}

As indicated earlier, this paper is drawn from a larger dissertation project; therefore, the data analysis was conducted on the entire data collected for the study. The data were transcribed and imported into NVivo qualitative data analysis software and were coded using several coding methods. First and second cycle coding were used in the process of developing categories and themes. Firstly, eclectic coding, which was a combination of two or more types of first cycle coding methods, was used [46]. A combination of descriptive, structural and holistic coding was used, which included theming the data. In this coding process, themes were created and different coded units were placed in the themes that were found to be appropriate. Descriptive coding was used to identify what the participants were saying, and topics were created as nodes that described what was perceived to be the meaning of the statement. Structural coding was used to outline some of the themes from past studies or theories and to code appropriate data into them from the interviews. For the section presented here, various topics guided by Chatman's framework of life in the round, such as determinants of worldview, social norms and small world, were created and different coded units were placed in each of the topics where appropriate. The process of holistic coding was also applied. In holistic coding, major issues that are relevant to answering the research questions are coded as a whole from the data. This could be an entire paragraph or even a whole text of a participant's response. Some statements were coded into multiple categories.

Secondly, after the categories were developed in the first cycle, the second cycle coding was conducted. In the second level coding, similar nodes were combined into sub-categories, and these were grouped under various categories that summed up a concept. All the different categories developed were condensed or matched into major categories that explain the phenomena under investigation. For instance, statements that indicated seeking information from people 
who are not clergy were placed under crossing boundaries. Statements that indicated seeking information only from another clergy on issues that pertain to other priests and the clergy's ministry were placed under the category of concern for privacy. Statements that indicated seeking information only within the clergy because one was more comfortable discussing a topic only with another priest, to seek his counsel, were placed under the category of insider advice. These categories: insider advice and concern for privacy were further placed into the major category of Staying within Clergy. Some nodes were eliminated because it was observed that they were not significant or did not meet relevant descriptions of the research questions that would enable them to be placed into created categories.

For validity and reliability, efforts were made to ensure the trustworthiness of the qualitative data. Data were painstakingly recorded and transcribed, and striking observations from participants' comments during the interviews were noted. The computer data analysis software Nvivo was used and the rules applied to enhance the reliability of the work. The transcript of each interview was sent to individual participants to review and report back if they agreed with the contents of what they said as transcribed. None objected to the contents, except for a few who pointed to some grammar errors they found in the scripts which they felt resulted because they were talking at the spur of the moment. Indeed, that only confirmed how naturally the conversation flowed without prepared text that could influence the true nature of the episodes they narrated. In addition, a few key participants were given copies of the draft report to review and report if it reflected the nature of their narratives or not. None of these participants raised any objection to the interpretation of the data.

\section{Findings}

The findings presented here are based on the research question: How does the small world of the Catholic clergy in Nigeria fit into Chatman's proposition that "members who live in the round will not cross the boundaries of their world to seek information"? In the direct quotes used to present the results below, real names and identifiable terms mentioned by the participants were replaced with pseudonyms or other terms, and placed in brackets. This was done to maintain the anonymity of the episodes. Participants' names were also represented by letter/number designation where P1 stands for participant one, P2 for participant two, etc. The categories and subcategories that were developed are presented below.

\subsection{Crossing boundaries for information}

There were some instances where participants stated that they sought information from people who were not clergy. These occasions were seen, for instance, when the information sought was already in the public domain or not necessarily related to the clergy. Such an instance was described by P11 when seeking information on politics and public affairs:

I also ask certain people because often times we know that the media is biased on certain issues, depending on those who are disseminating those pieces of information. So sometimes, like, OK, if an issue involves certain top government officials and if I happen to know any of them personally even after reading the piece of information, I could call the person and ask him, yeah, I read about this, or I listen about this in the news, what is really the situation? So through that I'm able to find out the truth. Sometimes if it is not as it was presented, he will say forget that it is not what it is, or this is how it is and things like that.

When a particular piece of information is vital, one participant said he goes the extra mile to get the information from people who are not clergy, especially when the priest wants to know what his parishioners think about him. There are times when the priest suspects his members are dissatisfied with his pattern of administration and he is experiencing some reactions. In this case, the priest tries to seek information from a few parishioners to help his decisions. P3 stated:

So when push comes to shove, then one picks here and there, what I consider mature lay persons. Maturity here means that they know what I know, and I know they know and they know I know they know, and they are ready to keep it to themselves. So whether it is criminal or whatever, for me it is maturity. So for these kinds of people I open up and try to get the kind of information I want from them.

When the information is relevant, especially on health issues, the clergy look for information outside. P6 narrated his experience of using his personal contacts when he sought information on health issues. In explaining who he uses he said:

Journal of Information Science, 2015, pp. 1-15 @ The Author(s), DOI: 10.1177/0165551510000000 
Maybe the nurses that I have around, and having the privilege of having a brother that is a medical doctor I also try to confirm and share with him my condition and explain the way I felt about my body and my system. And then he tried to tell me something, it could be typhoid, it could be malaria.

These statements demonstrate how these study participants step out of their boundaries to seek information from people that are not considered part of the group. This type of information is already in the public domain or it may be the type of information that does not raise question simply because the information seeker is a priest.

\subsection{Stay within clergy for information}

Most participants stated that there is information they would prefer to seek from a priest rather than a lay person, especially when it has to do with the issues of the church and the priests' private lives. According to P3, he believes there is information that stays within the circle of the priests exclusively because they share similar concerns; he gave this instance:

First of all, there was a given situation, because of the given situation I now went to ask priests directly whether they know anything about it, and you see those priests opening up to you because you are also a priest, believing that you can also keep it. So it is ahh, you know, it is within the circle.

When P3 was probed further to explain the type of information he was referring to, he stated:

Yeah, there are certain information I cannot go directly to ask the lay people, information that bothers about the life of another priest in danger, I will find it difficult to ask another lay person, but rather it will be around our circle. So information like that I will find it quite scandalous to even let the laity know that a thing like this can happen. For instance, where an information about a priest having a child out of unfaithfulness, I will find it difficult to ask a lay person but go through another priest in order to know how it all came about and how to go about it, how to solve certain problems.

P14 was asked if, as a celibate, the culture in which he lives in influences the way he looks for information from other people. He answered:

Definitely. Because it is not everybody you ask for information, and because of the high regards and respect people have for you as a celibate, sometimes even when you want to ask some persons for information that ordinarily people should not raise eyebrows on, you know. But when you begin to ask some information people begin to read some meanings into it.

Three reasons why they preferred to stay within the clergy for certain information are privacy concerns and the need for expert advice and insider advice.

\subsubsection{Privacy concerns}

Many participants expressed the need for privacy, especially if the issues are about fellow priests or are regarded as internal forum issues. According to P11:

Like when an issue particularly involves, let's say a priest, or certain inner things of the church, I will prefer to ask a priest rather than ask a lay person, generally. Except if I know that that layperson can really give me what I want. But otherwise, when it comes to those issues like that, I prefer to ask a priest. But any other business I could ask anybody. But when it matters to issues of the church, or certain secrets, or certain pieces of information that should not be divulged, I will prefer to ask a priest.

P8 preferred to stay within clergy for certain types of information to avoid causing scandal to a lay person who may not expect a demand for such information to come from the clergy. P8 said:

As a priest, there are so many things that have to do with me; therefore, if I want to ask or seek clarification, I meet a priest who can answer me, who will understand why I am asking that question and then he will answer me. There are things that I as a priest will go to lay people and ask them, and instead of them answering you, they will be scandalized. 
P3 talked about avoiding seeking certain health information from people who are not fellow clergy:

I find it difficult to ask for information concerning certain sicknesses like HIV. Let's say a priest who goes suffering from one or two things, I find it difficult to ask them how is that person going about it, is he really having this kind of problems here and there and there. Just a way of covering up. So I will not be too free to do that.

In the case of such sensitive health information, some would prefer using the Internet rather than ask people who are not clergy. P7 emphasized how the Internet has been a major source of information on such health issues:

Yes, yes. On the Internet, I Google it, I used the Google search engine. There are many materials on HIV on the Internet.

P14 explained how he preferred going through his colleagues who are clergy to gain insights about particularly sensitive issues especially on administration and finance because he believes they share similar experiences, opinions and concerns:

For example, information about running the day-to-day running of the parish as it concerns finance. Like in my present place of assignment, like the school we run here... We have an education committee, because if you leave it to the lay people, their formation is quite different from ours. So in getting certain information as regards finance, it's not as if one is trying to be secretive or that one is hiding anything. But because their formation is quite different from ours. Sometimes if you go too far, or you are too open, you will be misinterpreted and also misrepresented. So at such moments, I try to ask those that have worked here previously for such information.

P6 believed that the expectations of the people contribute to reasons why the clergy may prefer seeking information among themselves:

Most times when you are different you just attract questions, yeah, when you are different you just attract questions. So most times the priest and celibate appear different from the rest of the people. Most times they eh, you live as a suspect, yeah, most people suspect you when they see you, because your life is counter-natural, it's just abnormal. So they suspect, whatever you do, they suspect you. Most times when you go to seek information as a priest, when they see you close to women, sometimes they want to see the way you react whether you look at them the way they look at them or whatever. So they suspect at times. When you go to look for information from the opposite sex, at times, you fear the freedom; at times, your freedom will be restricted in a certain way at times so that you don't attract questions or give people opportunity to talk. It at times affects one, because you are now conscious, because of your state, who to relate with when and how.

\subsubsection{Expert and insider advice}

The desire for advice from one that is regarded as an expert keeps some clergy from asking those who are not clergy for information, especially on issues regarding the church and the ministry of the clergy. Some of the participants reported that they seek information on teachings of the Church from people, most of whom are fellow priests who are regarded as experts in the area of interest. P14 narrated an episode of his experience on what he does:

...particularly on liturgy, area of liturgy. Mostly I have about three persons whose main area of specialization has to do with liturgy [names removed]. Sometimes certain feasts and solemnities come up that one is confused about what to do and the position of the church on them. Like today that happens to be the memorial of ahhm..., no sorry, yesterday, the memorial of St. Martin de Porres. The liturgical calendar here indicated Green and at the same time memorial. So when I find myself in situation like that I called these people to inquire what will be the realistic thing to do. And also on marital issues, marital issues, the canon law has specified guidelines and regulations regarding them. Sometimes with the uniqueness of our cultural context here, certain situations come up that you have to search, or ask for information from other experienced priests. For example, [names removed] who are specialists in that area. So I definitely ask, call them once in a while when faced with such situations to get the expert recommendation.

P1 talked about how he relied on fellow priests who are experts in a particular field for information on certain subjects because he viewed the information coming from them as reliable and trustworthy: 
Like when you come to canon law, you know, when you come to canon law there is a particular priest we go to. When it comes to liturgy, there is a priest we go to, and when it comes to the history of a particular church, we try to see the eldest priest among all the priests that have served.

They also prefer to seek counsel from within because of the awareness that an insider has an understanding of the experience and problems of the priesthood. P13 narrated what makes him prefer a fellow priest:

...well, you know about this issue of celibacy, how priests cope with it. You know one cannot ask a layman because entirely his own vocation is different or her own vocation is completely different from ours. So I try to ahh, sometimes ahh, one is a full-fledged man, let's be realistic, hale and happy, body and soul. So there may be moments that one may have this sexual urge, then the thoughts keep on coming: how does it ahh, and how one copes. So sometimes one will quickly run to ask. So when one goes to ask a lay person, somebody who is married, he doesn't really understand, he doesn't share in our own pain because he is not a priest. So I can only run to a priest who shares the same pain with me. Ok, I don't know whether you've had this kind of experience before? If he says yes, how were you able to cope? The person will just tell me, "Father you see sometimes, when the urge is coming that shows that you are a human being and you are healthy. Because if you are not healthy first and foremost you wouldn't have been admitted into the seminary to become a priest. So we need full-fledged men who would now understand the pain of what they are sacrificing and that's just it. And then sometimes when such thoughts are coming, what you need do, you need to pray because a lot of people have conquered through prayer. Then all you need do, read spiritual books, just engage yourself, go for exercise, read a lot of literature that are positive, yes. And then you will conquer.

P2 explained that when it comes to the challenges of his ministry, the first run-to person is a fellow priest:

Of course, of course, there are so many things that I preferred to ask my fellow priests about, and mostly it has to do with the pastoral challenges I face as a parish priest. Sometimes certain situations come up and one is at a loss; you begin to think what do you do in this kind of situation. So you quickly want to seek information from a higher authority, and there are people you know are there in the priesthood before you. So these are not information that you can just go and ask any lay person. Things that have to do with the pastoral life, pastoral challenges, I preferred to ask a priest than any layperson.

The statements of the participants in this section of the findings show how this group of people prefer to seek certain information, especially those that pertain to their private lives and ministry, only from those that are members of the group with whom they share the same worldview and social norms.

\section{Discussion}

The findings of this study agreed with the initial assumption that the Catholic clergy in Northern Nigeria live in a small world based on their social norms. Their social norms are guided by their religious status as Catholic clergy. They are aware that people place high expectations on them, and this awareness compels them to live and act in a certain way, which affects their public behavior, including information seeking. This was in agreement with Chatman, in that when private behavior receives increased public scrutiny because of the social norms held by a group, it influences members of the group to determine what information seeking behavior is deemed appropriate or not [2]. These features of the small world of these Catholic clergy, together with their social norms and worldview, positioned them to be described as living in the round. This study intends to find out whether the small world of the Catholic clergy in Nigeria fit into Chatman's fifth proposition of the theory of life in the round that members of a small world who live in the round will not cross the boundaries of their world to seek information.

\subsection{Determining life in the round}

From the analyses of the small world of these clergy, especially their social norms and worldview, the Catholic clergy in Northern Nigeria, in their process of seeking information, tend to either stay within the clergy or cross boundaries, depending on what type of information they need. This is mostly in relation to the people sources they use to seek information. 


\subsubsection{Crossing boundaries}

The study found that for certain information needs, especially concerning things and events such as politics, health, security, and products to buy, these clergy cross the boundaries of their small world to seek information. These types of information tended to be in the public domain and may not be related to their private lives as clergy; in this situation they expressed more willingness to seek information from those who are not clergy members.

Chatman provided a sixth proposition that could explain a situation when the fifth proposition does not hold. According to Chatman:

Individuals will cross information boundaries only to the extent that the following conditions are met: (1) the information is perceived as critical, (2) there is a collective expectation that the information is relevant, and (3) a perception exists that the life lived in the round is no longer functioning. [2, P. 214]

There is an indication from the data that, when some information is vital to these clergy, they will cross boundaries to seek such information. Vital information could be information that the priest feels others know about him that he may not be aware of, for instance, when the priest perceives that his parishioners are grumbling over issues at the parish, especially over his administrative decisions. Some clergy may seek information from parishioners in order to address issues. In the case of relevant information such as health issues, it is not surprising that they seek information from outside their group. Hence the sixth proposition provides, at least in part, some reasons why these clergy could cross the boundaries of their world. However, the data showed a very functional small world where members are very conscious of their way of life. Hence, the third condition of Chatman's sixth proposition was not supported from the data.

\subsubsection{Staying within their world}

When the clergy need information on topics such as those concerning their ministry, pastoral problems, and issues concerning the church, they tend to seek such information through their fellow clergy. There are three major reasons why they prefer to stay within the clergy for these types of information. These are privacy concerns, the need for an expert and the need for an insider adviser.

There are issues that are considered private to these clergy and are expected to remain among the clergy. Their social norms and worldview lead to certain protective behaviors of members. Consequently, they will likely prefer not to discuss certain issues with non-members, even if that discussion may lead to gaining some information. At other times, they may prefer not to ask people who are not Catholic clergy for certain information in order to avoid the scandal that such a question may cause to the lay person. Issues concerning sex or some type of sexually transmitted disease like HIV may be seen as information that the lay person may not expect the priest to seek. This is connected to the fact that the Catholic priest is a celibate and expected to remain chaste. Hence, the lay person may not expect him to need information with any type of sexual connotation. In order to avoid the misunderstanding this might cause to the lay person, the clergy may prefer to avoid seeking this type of information from those who are not clergy. At most, they may use Internet searches to learn more. This results in selective information seeking leading to information avoidance or selective exposure to information where people only seek information that are in conformity with their beliefs, knowledge and opinion and avoid any other information to the contrary [47, 48]. According to Schramm [49] this may be influenced by qualities such as social status of the individual. In the case of these clergy, their religious status as clergy, with the effect of their worldviews and social norms, could be contributing factors.

Another reason they stay within the group is for insider advice. This goes back to the trust they have for fellow clergymen, and the belief that, as one of them, he will understand their need. These clergy will most likely seek counsel from certain fellow clergy who are considered insiders and are very familiar or experienced in the ministry. They tend to believe that these clergy share their experiences and understand the problems of a celibate clergy. They are less likely to consult with someone such as a counselor or psychologist who is not a member of the clergy about their private lives, especially on the challenges of celibacy.

These clergy might also prefer to seek information only among themselves because of the need for an expert adviser. On issues regarding the teachings of the church, for instance, the clergy have some among them who are considered experts in different fields such as liturgy, scriptures, and moral theology. Other clergy members will most likely prefer to seek information from these clergy experts rather than from someone who is not clergy, even if the person has an equivalent qualification. They may not see the need to seek information outside because of the awareness that there are experts among them.

Therefore, when these clergy sought information conscious of their religious status as Catholic clergy, their attitudes supported Chatman's fifth proposition that those who live in the round do not cross boundaries of their world to seek 
information. Consequently, these attitudes have the tendency to negatively affect the information seeking of these clergy by preventing them from access to relevant information in the hands of outsiders.

To sum up, at first look, this study supports Chatman's fifth proposition of the theory of life in the round only to a certain extent. When they need information about their ministry and private lives as Catholic clergy, this group of people do not cross boundaries of their small world to seek information. However, when they need information about things such as security, politics, and products to buy, these clergy tend to cross the boundaries of their world to seek information. These findings also support the results of Wicks, who found that when clergy seek information within their world, they operate in a closed system, but when they seek information outside their world, they operate in an open system [39].

As shown in the review of literature, Wicks studied pastoral clergy to determine the work worlds and the work roles that guide how they search for information. He found that the work worlds and work roles of the clergy influence their information seeking behavior so that it takes place in either a closed or an open system. A closed system exists when the clergy seek information only within their world, and an open system exists when they seek information outside their world. This is similar to the contextual variables that influence information need as described by Leckie [50], which can be either internally or externally prompted. Wicks' work supported Chatman [2] to a certain extent, by confirming that members of a small world do not go outside their boundaries to seek information. However, while Chatman concentrated on non-work everyday life information seeking, Wicks believed that the information seeking behavior of the clergy is determined by work worlds and work roles.

The present study conceptualized the information seeking [51] of a group of clergy within a small world. Although the findings show that these clergy sometimes cross boundaries to seek certain information, Chatman indicated that the type of information the theory of life in the round refers to is that which responds to the needs of individuals within a particular social context (i.e., the information needed to solve problems). For these clergy, this is the information about their ministry and private lives. In this case, the findings show that these Catholic clergy in Northern Nigeria are not likely to cross boundaries of their small worlds to seek information about their ministry or private lives. They prefer to seek such information within their circle of clergy. This behavior is referred to in this study as seeking information in circles. Therefore, the findings of this study align with Chatman's proposition that members who live in the round will not cross the boundaries of their world to seek information. In other words, the effects of factors such as worldviews, social norms and environment of these Catholic clergy may lead to life lived in the round, which consequently may affect the movement of information in and out of a small world. This may consequently have negative effects on information seeking behavior. When the clergy do not cross the boundaries of their world to seek essential information, it hinders access to relevant information that outsiders possess, and may subsequently lead to information poverty [14]. This agrees with Childers and Post [52, p. 43] that when an individual is "locked into an informal information network that is deficient in the information that is ordinarily available to the rest of the society" it may lead to information poverty. Wilson [53] believes that this condition can sometimes be self-selected and freely entered into and, in some cases, willingly endured by the individual. This appears to be the case with the clergy in this study where the need to preserve self-protective behaviors results in avoidance of some vital information sources. They are, however, likely unaware of their small-world pattern of behavior.

\section{Theoretical implications}

The study contributes to Chatman's concept of the small world, especially to the theory of life in the round. It supports Chatman's proposition that members who live in the round will not cross the boundaries of their world to seek information. It shows that the small world of the Catholic clergy in Northern Nigeria fits into Chatman's theory of life in the round. The study shows that worldviews and social norms of a group of people identified by their religious status are factors that may lead to living life in the round, which may negatively influence information seeking. In addition to the theory of life in the round, this study contributes to other theories of Chatman [1, 14].

Chatman's theories were mostly developed around the poor and marginalized people of society. This study advances our understanding of Chatman's theory of life in the round by showing that it could also be applicable to a set of people that may not be considered marginalized, but in every sense of the word, are privileged people who occupy positions of influence because of their religious status as clergy. The findings agree with Chatman that information poverty is likely caused by other factors that may be unrelated to economic ones, as in the case of these Catholic clergy, where the main aspect of their chosen religious life-style could lead to "self-protective behaviors which are used in response to social norms" [14, p. 197]. This may lead to information deprivation. 
In conclusion, this study showed the difficulties that clergy face in using people sources for information. This could likely be linked to the demands of the environment, culture, the social norms and worldviews resulting from being Catholic clergy. The study may provide information professionals and system developers with data needed to become cognizant of the particular environment in which the clergy live, in order to make appropriate information available and accessible. It creates awareness of the contextual differences of the information environment of the clergy so that information services can be provided to them according to their settings and problems. As the findings showed, restricting seeking information to clergy members alone may have a negative effect on the variety of information the clergy acquire. Therefore, seminary educators involved in the training of seminarians should develop programs that will prepare future clergy for the social and cultural challenges that come with information seeking, which happens not just in their work roles as clergy, but as everyday members of the community. This study uses only Catholic clergy from Northern Nigeria. Future study may examine Catholic clergy from other parts of the world and compare the findings of this study to see whether there are differences based on culture or other factors such as perception of celibacy, community, or social life.

\section{Funding}

This research received no specific grant from any funding agency in the public, commercial, or not-for-profit sectors.

\section{Acknowledgements}

The author would like to thank Dr. Shawne Miksa and Dr. Elizabeth Figa, associate professors at the University of North Texas, Denton, and Dr. Lisa Heinrich, Professor at St. Cloud State University, Minnesota, for their assistance throughout the process of conducting this study.

\section{References}

[1] Chatman EA. Life in a small world: Applicability of gratification theory to information-seeking behavior. Journal of the American Society for Information Science 1991; 42: 438-49.

[2] Chatman EA. A theory of life in the round. Journal of the American Society for Information Science. 1999; 50: $207-17$.

[3] Chatman EA. Information, mass media use and the working poor. Library \& Information Science Research 1985; 7: 97-113.

[4] Chatman EA. The Information World of Low-Skilled Workers. Library and Information Science Research 1987; 9: 265-83.

[5] Chatman EA. Diffusion theory: A review and test of a conceptual model in information diffusion. Journal of the American Society for Information Science 1986; 37: 377-86.

[6] Chatman EA. The information world of retired women. Westport, CT: Greenwood Publishing Group, 1992.

[7] Thompson KM. Remembering Elfreda Chatman: A champion of theory development in library and information science education. Journal of Education for Library and Information Science 2009: 119-26.

[8] Pollock N. Conceptualising the Information Poor: An Assessment of the contribution of Elfreda Chatman towards an understanding of behaviour within the context of information Poverty, http://npollock.id.au/info_science/chatman.html (2002, accessed 11 May 2014).

[9] Edwards SL. Re-conceptualizing the information use environment: Enablers of and constraints to human information behavior in hospice care volunteerism in the Southeastern Appalachian region. PhD Thesis, University of Tennessee, USA, 2012.

[10] Folb BL, Detlefsen EG, Quinn SC, et al. Information practices of disaster preparedness professionals in multidisciplinary groups. Proceedings of the American Society for Information Science and Technology 2010; 47: 1-9.

[11] Kazmer MM, Glueckauf RL, Ma J, et al. Information use environments of African-American dementia caregivers over the course of cognitive-behavioral therapy for depression. Library \& Information Science Research 2013; 35: 191-9.

[12] Pettigrew KE, Fidel R and Bruce H. Conceptual frameworks in information behavior. Annual review of information science and technology 2001; 35.

[13] Dankasa J. Information use environment of religious professionals: A case study of the everyday life information seeking behavior of Catholic clergy in Northern Nigeria. PhD thesis, University of North Texas, Denton, USA, 2015.

[14] Chatman EA. The impoverished life-world of outsiders. Journal of the American Society for Information Science 1996; 47: 193-206.

[15] Spink A and Cole C. Human information behavior: Integrating diverse approaches and information use. Journal of the American Society for Information Science \& Technology 2006; 57: 25-35.

[16] Carey RF, McKechnie LE and McKenzie PJ. Gaining access to everyday life information seeking. Library \& Information Science Research 2001; 23: 319-34.

[17] Jaeger PT and Burnett G. Information Worlds: Social Context, Technology, and Information Behavior in the Age of the Internet. New York: Routledge, 2010.

[18] Taylor RS. Value-added processes in information systems. Norwood, NJ: Ablex, 1986. 
[19] Taylor RS. Information use environments. In: Voigt BDMJ, (ed) Progress in Communication Sciences. Norwood, NJ: Ablex, 1991, pp. 217-54.

[20] Hersberger J. Are the economically poor information poor? Does the digital divide affect the homeless and access to information? Canadian journal of information and library science 2002; 27: 45-63.

[21] Le Dantec CA and Edwards WK. Designs on dignity: perceptions of technology among the homeless. Proceedings of the SIGCHI conference on human factors in computing systems 2008, p. 627-36.

[22] Musa AI. Chatman's theories of information behavior (1996, 1999, 2000). In: Al-Suqri MN, (ed) Information Seeking Behavior and Technology Adoption: Theories and Trends 2015, pp. 136-48.

[23] Yu L. Towards a reconceptualization of the information worlds of individuals. Journal of Librarianship and Information Science 2012; 44: 3-18.

[24] Burnett G and Jaeger PT. Small worlds, lifeworlds, and information: The ramifications of the information behaviour of social groups in public policy and the public sphere. Information Research 2008; $13: 7$.

[25] Cooke NA. The information use behaviors of graduate students in an online learning community. PhD Thesis, The State University of New Jersey, New Brunswick, USA, 2012.

[26] Huotari ML and Chatman E. Using everyday life information seeking to explain organizational behavior. Library \& Information Science Research 2002; 23: 351-66.

[27] Savolainen R. Small world and information grounds as contexts of information seeking and sharing. Library \& Information Science Research 2009; 31: 38-45.

[28] Wachanga DN. Sanctioned and controlled message propagation in a restrictive information environment: The small world of clandestine radio broadcasting. PhD Thesis, University of North Texas, USA, 2007.

[29] Fulton C. An ordinary life in the round: Elfreda Annmary Chatman. Libraries \& the Cultural Record 2010; 45: $238-59$.

[30] Agada J. Inner-city gatekeepers: An exploratory survey of their information use environment. Journal of the American Society for Information Science 1999; 50: 74-85.

[31] Lingel J and Boyd DM. "Keep it secret, keep it safe": Information poverty, information norms, and stigma. Journal of the American Society for Information Science and Technology 2013; 64: 981-91.

[32] Pollak A. "Like a boxer in a boxing match-punch drunk": The information world of a master electrician. Proceedings of the Annual Conference of CAIS/Actes du congrès annuel de l'ACSI, http://www.caisacsi.ca/ojs/index.php/cais/article/viewFile/146/527 (2013, accessed 5 June 2014).

[33] Michels DH. Dipping into a shallow pool or beginning a deeper conversation: A case study of a minister's engagement with the internet for preaching. Journal of Religious \& Theological Information 2009; 8: 164-78.

[34] Park JZ and Taylor CR. Information resources of elite ministry professionals. Review of religious research 2007: 428-36.

[35] Roland DR. Interpreting scripture in contemporary times: A study of a clergy member's sense-making behavior in preparing the sunday sermon. PhD Thesis, ProQuest \& Theses Database, 2008.

[36] Van DL. How the Internet shapes religious life, or the medium is itself the message. Bulletin of Science, Technology \& Society 2009; 29: 272-7.

[37] Curran CC and Burns K. Methodology for studying the information seeking of catholic clergy. Advances in the Study of Information and Religion 2011; 1. http://digitalcommons.kent.edu/cgi/viewcontent.cgi?article=1025\&context=asir (accessed 11 April 2013).

[38] Lambert JD. The information-seeking habits of Baptist ministers. Journal of Religious \& Theological Information 2010; 9: 119.

[39] Wicks DA. The information-seeking behavior of pastoral clergy: A study of the interaction of their work worlds and work roles. Library \& Information Science Research 1999; 21: 205-26.

[40] Bakar ABA and Saleh AG. A survey of information resources required by Ulama to perform their work roles: A case study of Borno state, Nigeria. Library Philosophy and Practice, http://unllib.unl.edu/LPP/bakeri-saleh.htm (2011, accessed 6 July 2013).

[41] Saleh AG and Bakar A. Information-seeking behavior of the Ulama in relation to preaching and counseling roles in Nigeria. Theological Librarianship 2013; 6: 29-46.

[42] Saleh AG and Sadiq H. The influence of denominational affiliations on the information seeking behavior of the ulama in Borno state, Nigeria. Annals of Library and Information Studies 2012; 59: 79-89.

[43] Dankasa J. Information-seeking behavior of clergy: The research, the results, and the future. Journal of Religious \& Theological Information 2015; 14: 13-29.

[44] Creswell JW. Research design: Qualitative, quantitative, and mixed methods approaches. 3rd ed. London: Sage, 2009.

[45] Flick U. Episodic interviewing. In: Bauer M and Gaskell G, (eds) Qualitative researching with text, image and sound: A practical handbook London: Sage Publications, 2000, pp. 75-92.

[46] Saldaña, J. The coding manual for qualitative researchers. 2nd ed. Los Angeles: Sage Publications, Inc., 2013

[47] Narayan B, Case DO and Edwards SL. (2011). The role of information avoidance in everyday-life information behaviors. Proceedings of the American Society for Information Science and Technology, 2011; 48: 1-9.

[48] Case DO. Looking for information: a survey of research on information seeking, needs, and behavior. 3rth ed. UK: Emerald Group Publishing Ltd, 2012. 
[49] Schramm W. Channels and audiences. In: Pool I, Schramm W, Maccoby N and Parker E, (eds), Handbook of communication Chicago, IL: Rand McNally, 1973, pp. 116-140.

[50] Leckie GJ, Pettigrew KE and Sylvain C. (1996). Modeling the information seeking of professionals: A general model derived from research on engineers, health care professionals, and lawyers. The Library Quarterly 1996; 161-193.

[51] Savolainen R. Everyday life information seeking: Approaching information seeking in the context of 'way of life.' Library \& Information Science Research 1995; 17: 259-294.

[52] Childers T and Post J. The information-poor in America. Metuchen, NJ: Scarecrow, 1975.

[53] Wilson P. Second-hand knowledge: An inquiry into cognitive authority. Westport, CT: Greenwood Press, 1983. 